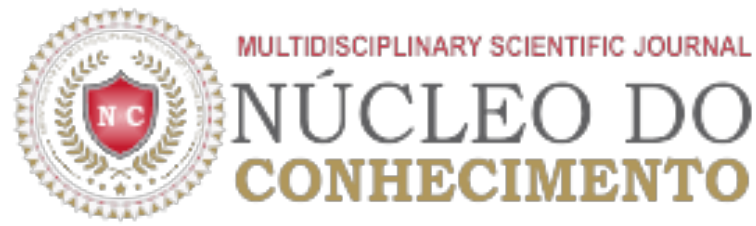

\section{Panorama brasileiro de tungstênio (w) entre os anos de 2008 e 2014}

BARROS, Yara Lorrane Souza ${ }^{[1]}$, ARAÚJO, Franciolli da Silva Dantas $\stackrel{[2]}{\text {, FECURY, Amanda Alves }}{ }^{[3]}$, OLIVEIRA, Euzébio ${ }^{[4]}$, DENDASCK, Carla Viana ${ }^{[5]}$, DIAS, Claudio Alberto Gellis de Mattos ${ }^{[6]}$

BARROS, Yara Lorrane Souza. Et al. Panorama brasileiro de tungstênio (w) entre os anos de 2008 e 2014. Revista Científica Multidisciplinar Núcleo do Conhecimento. Ano 03, Ed. 09, Vol. 08, pp. 22-29 Setembro de 2018. ISSN:2448-0959, Link de acesso: https://www.nucleodoconhecimento.com.br/quimica/tungstenio ?

\section{RESUMO}

Os minerais são substâncias químicas naturais, que possuem estrutura interna ordenada, e certas características constantes que permitem sua identificação como mineral. O tungstênio (W) é uma substância química que possui ponto de fusão de $3.419^{\circ} \mathrm{C}$, e peso específico de $19,3 \mathrm{~g} / \mathrm{cm} 3 \ldots$ Existem cerca de 20 minerais que contém tungstênio na sua composição química, sendo a scheelita e a volframita os principais. Os dados foram retirados do Departamento Nacional de Produção Mineral - DNPM (http://www.dnpm.gov.br/). A compilação dos dados foi feita dentro do aplicativo Excel, componente do pacote Office da Microsoft Corporation. A pesquisa bibliográfica foi realizada em artigos científicos encontrados na rede mundial de computadores. Os dados mostram que entre 2008 e 2010 houve um declínio na produção de tungstênio na forma de mineral contido e concentrado. A partir do ano de 2011 a produção cresceu. O Brasil exportou quase o quádruplo do que importou de tungstênio no período pesquisado. Entre os anos de 2008 e 2012 houve um crescimento no consumo aparente do tungstênio. Em 2013 e 2014 nota-se uma acentuada queda em relação aos demais anos. O quadro brasileiro do tungstênio demonstrou dificuldades, mas continuou crescendo, trazendo pesquisas que podem melhorar o consumo e produção da matéria-prima no território nacional.

Palavras-chave: Tungstênio, Produção, Consumo, Comércio.

\section{INTRODUÇÃO}

Minerais são substâncias químicas naturais, que possuem estrutura interna ordenada, e certas características constantes que permitem sua identificação como mineral. Características como: 
composição química e propriedades físicas próprias. Minério é o termo utilizado para se referir a um ou mais minerais, com viabilidade economia e tecnológica (BRASIL, 2016; NORONHA, 2017).

A concentração dos minerais de interesse econômico na crosta terrestre é denominada de recurso mineral. Esta apresenta condições razoáveis para extração econômica. O recurso mineral possui localização, teor, quantidade, características geológicas e outras características conhecidas, ou estimadas. A parte economicamente lavrável do recurso mineral designa-se de reserva mineral (BRASIL, 2016).

O tungstênio (W) é uma substância química que possui ponto de fusão de $3.419^{\circ} \mathrm{C}$, e peso específico de 19,3g/cm3... Existem cerca de 20 minerais que contém tungstênio na sua composição química, sendo a scheelita e a volframita os principais. O tungstênio metalizado possui dureza elevada, resistência ao desgaste e à corrosão, resistência a elevadas temperaturas e é um bom condutor de calor e energia (CANO et al., 2009). Este é um minério de coloração cinza aço, pertencente ao grupo 6 da tabela periódica, na $3^{\mathrm{a}}$ linha. Possui o maior ponto de fusão dos metais, ponto de ebulição igual a $5555{ }^{\circ} \mathrm{C}$ e peso específico igual a 19,3 g/m3. Existem cerca de 20 minerais de tungstênio, sendo a scheelita e volframite os principais. O primeiro uso comercial de tungstenite foi em aditivos para endurecer aços em 1868 (PAULINO e AFONSO, 2013).

O tungstênio pode ser comercializado de três formas: concentrado, produto intermediário, e produto final. Dentre os produtos intermediários destacasse alguns ferrotungstênio e compostos químicos. Entre os produtos finais derivados da indústria de transformação de tungstênio, existe o tungstênio metálico, aços especiais, ligas não ferrosas, dentre outros (CANO et al., 2009).

\section{OBJETIVO}

Apresentar o quadro do tungstênio no comércio nacional, podendo servir de base para empresas e pesquisadores entenderem o mercado do tungstênio brasileiro. O objetivo deste trabalho é mostrar o panorama brasileiro de tungstênio (W) entre 2010 e 2014, e nacional dentre 2008 e 2014.

\section{MÉTODO}

Os dados foram retirados do Departamento Nacional de Produção Mineral - DNPM (http://www.dnpm.gov.br/). Na página inicial, no tópico "Acervo", selecionou-se a aba "Publicações". Clicou-se no ícone da opção "Estatística e Economia Mineral". Na nova página que se abriu foi selecionado o ícone do título "Sumário Mineral". Foram baixados em PDF os sumários dos anos de 2010 a 2014 e foram coletados os dados relativos ao estanho das tabelas "Reservas e produção mundial" e "Principais estatísticas - Brasil". A compilação dos dados foi feita dentro do aplicativo Excel, componente do pacote Office da Microsoft Corporation. A pesquisa bibliográfica foi realizada em artigos científicos encontrados na rede mundial de computadores, feita em máquinas do laboratório de informática do Instituto Federal de Educação, Ciência e Tecnologia do Amapá, Campus Macapá, situado à Rodovia BR 210 KM 3, s/n - Bairro Brasil Novo. CEP: 68.909-398, Macapá, Amapá, Brasil. Os dados foram organizados no aplicativo Excel, componente do pacote Office da Microsoft Corporation.

\section{RESULTADOS}

A Figura 1 apresenta os dados da produção de tungstênio em forma de mineral contido no Brasil entre os 
anos de 2008 e 2014 (t). Os dados mostram que entre 2008 e 2010 houve um declínio na produção de tungstênio na forma de mineral contido. A partir do ano de 2011 a produção cresceu.

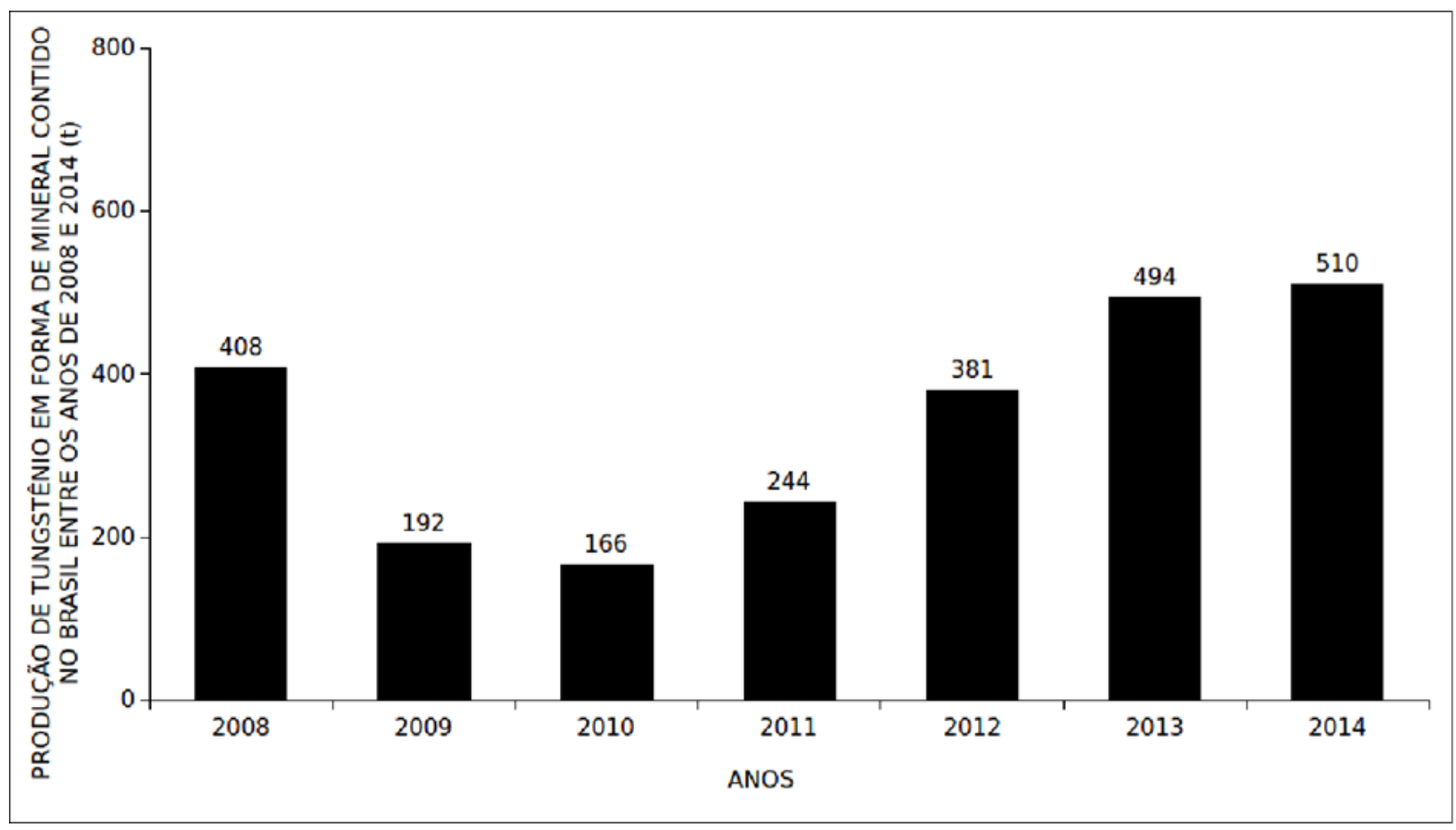

Figura 1: Produção de tungstênio em forma de mineral contido no Brasil entre os anos de 2008 e 2014 (t).

A Figura 2 apresenta os dados da produção de tungstênio em forma de mineral concentrado no Brasil entre os anos de 2008 e $2014(\mathrm{t})$. Os dados mostram que entre 2008 e 2010 houve um declínio na produção de tungstênio em forma de mineral concentrado. A partir do ano de 2011 a produção cresceu. 


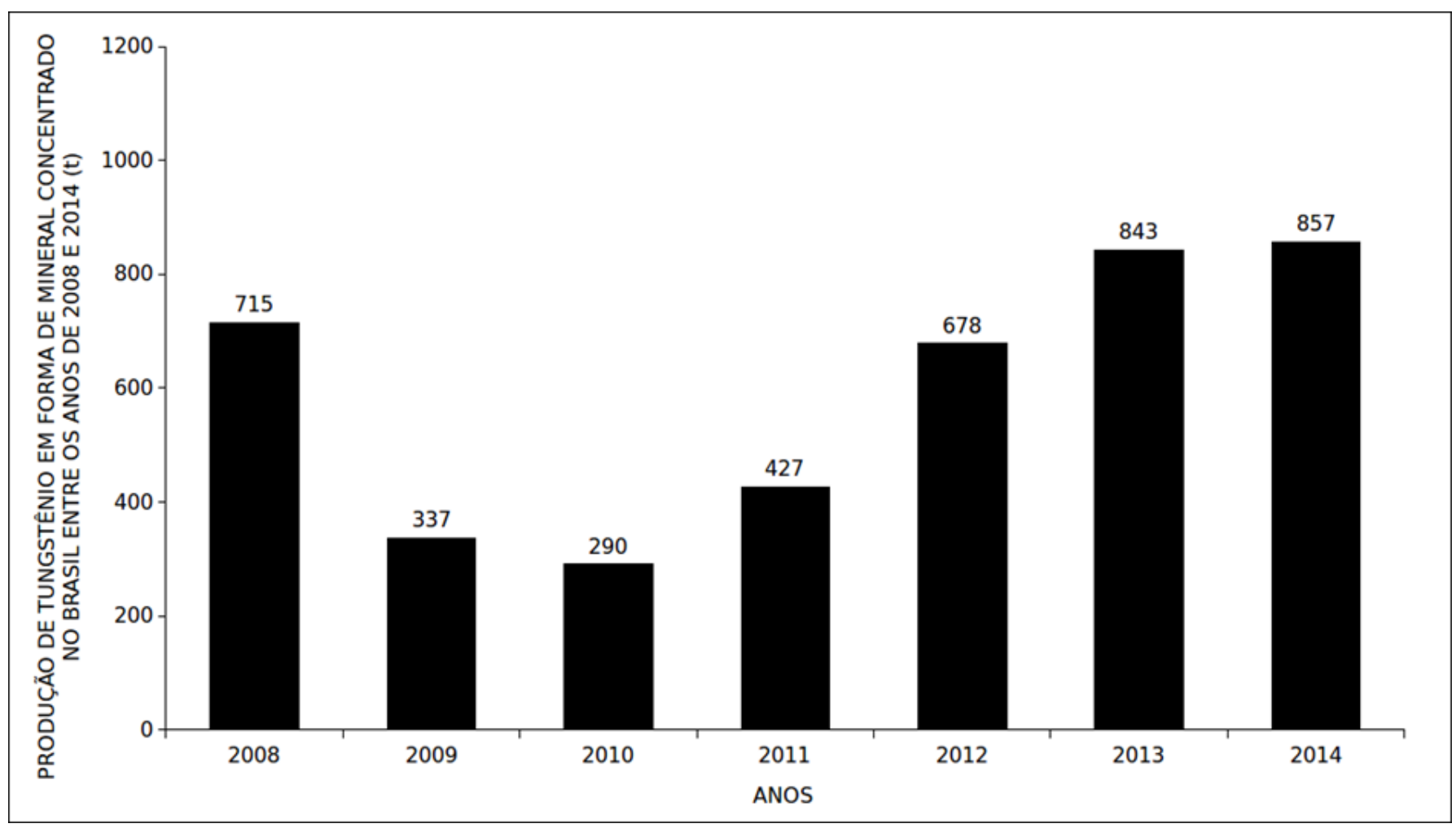

Figura 2: Produção de tungstênio em forma de mineral concentrado no Brasil entre os anos de 2008 e $2014(\mathrm{t})$.

A Figura 3 apresenta os dados de importação e exportação de tungstênio no Brasil entre os anos de 2008 e 2014 (t). Os dados mostram que o Brasil exportou quase o quádruplo do que importou de tungstênio no período pesquisado. 


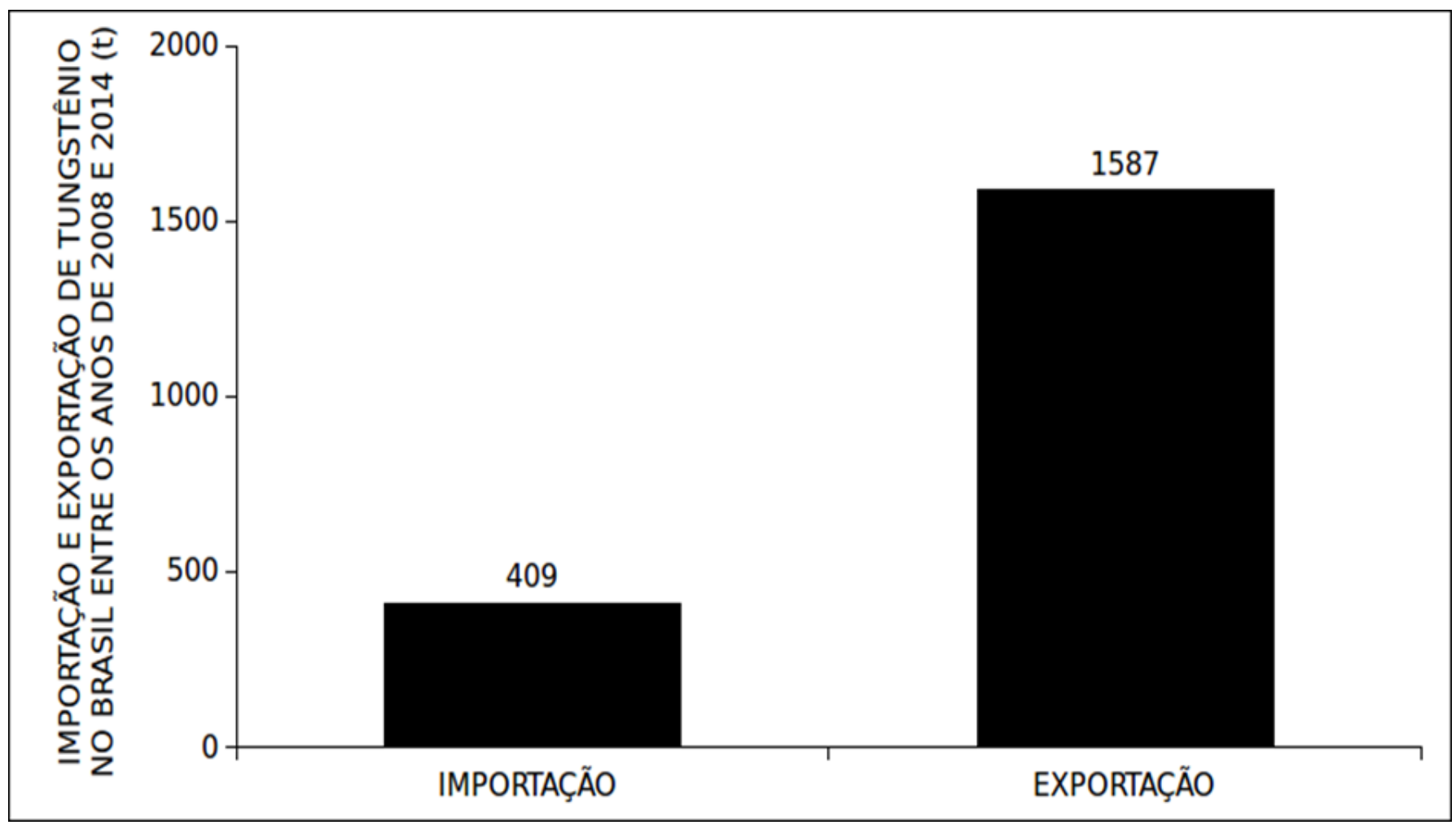

Figura 3: Importação e exportação de tungstênio no Brasil entre os anos de 2008 e 2014 (t).

A Figura 4 apresenta os dados do preço médio anual do tungstênio em forma de mineral concentrado entre os anos de 2008 e 2014 (US\$/MTU-CIF). Os dados mostram que o preço apresentado pela EUAPlatts Metals Week foi quase três vezes maior que o preço apresentado pela Europe-London Metal Bulletin. 


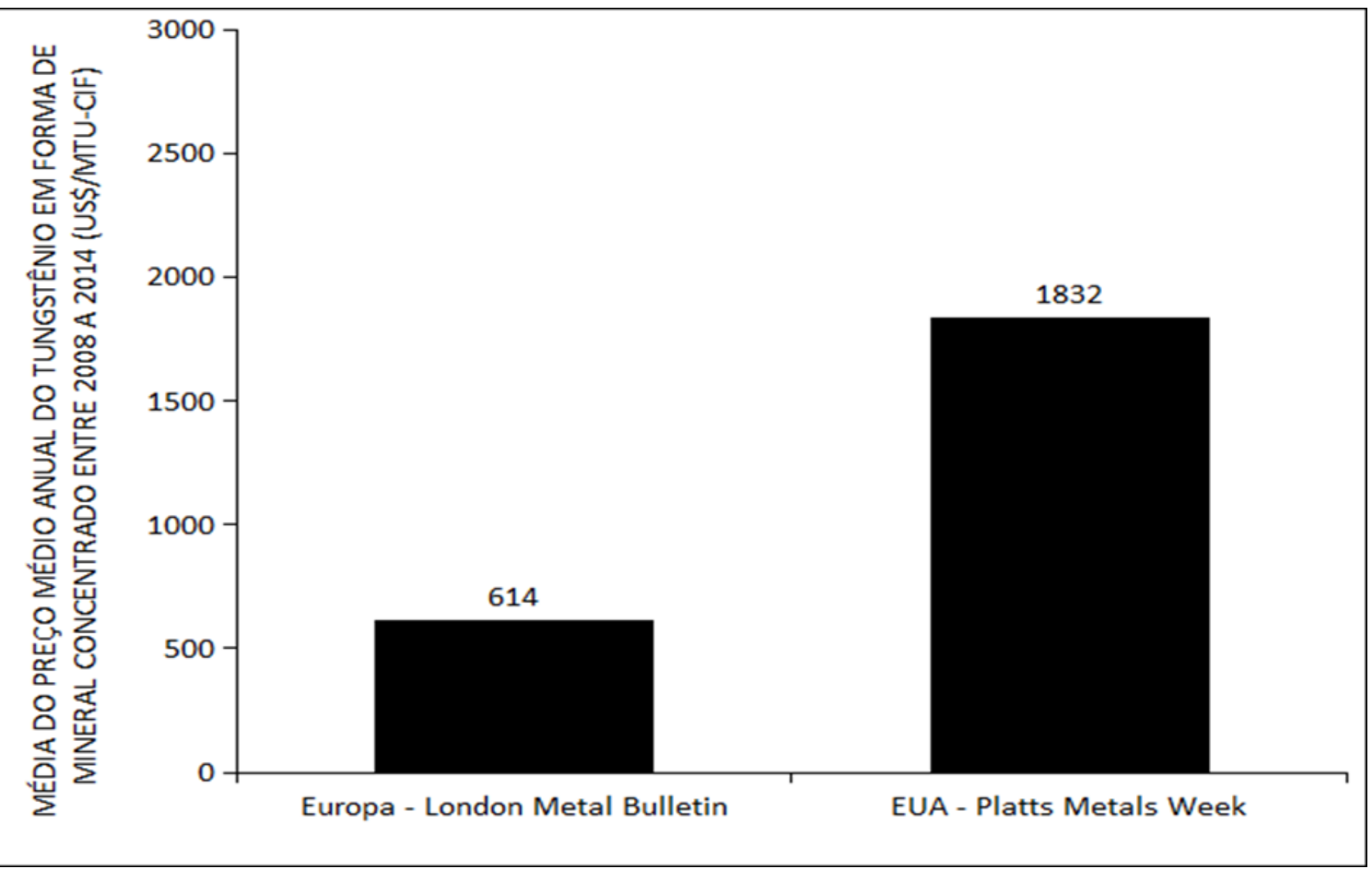

Figura 4: Média do preço médio anual do tungstênio em forma de mineral concentrado entre os anos de 2008 e 2014 (US\$/MTU-CIF).

A Figura 5 apresenta os dados do consumo aparente de tungstênio em forma de mineral concentrado no Brasil entre os anos de 2008 e 2014 (t). Os dados mostram que entre os anos de 2008 e 2012 houve um crescimento no consumo aparente. Em 2013 e 2014 nota-se uma acentuada queda em relação aos demais anos. 


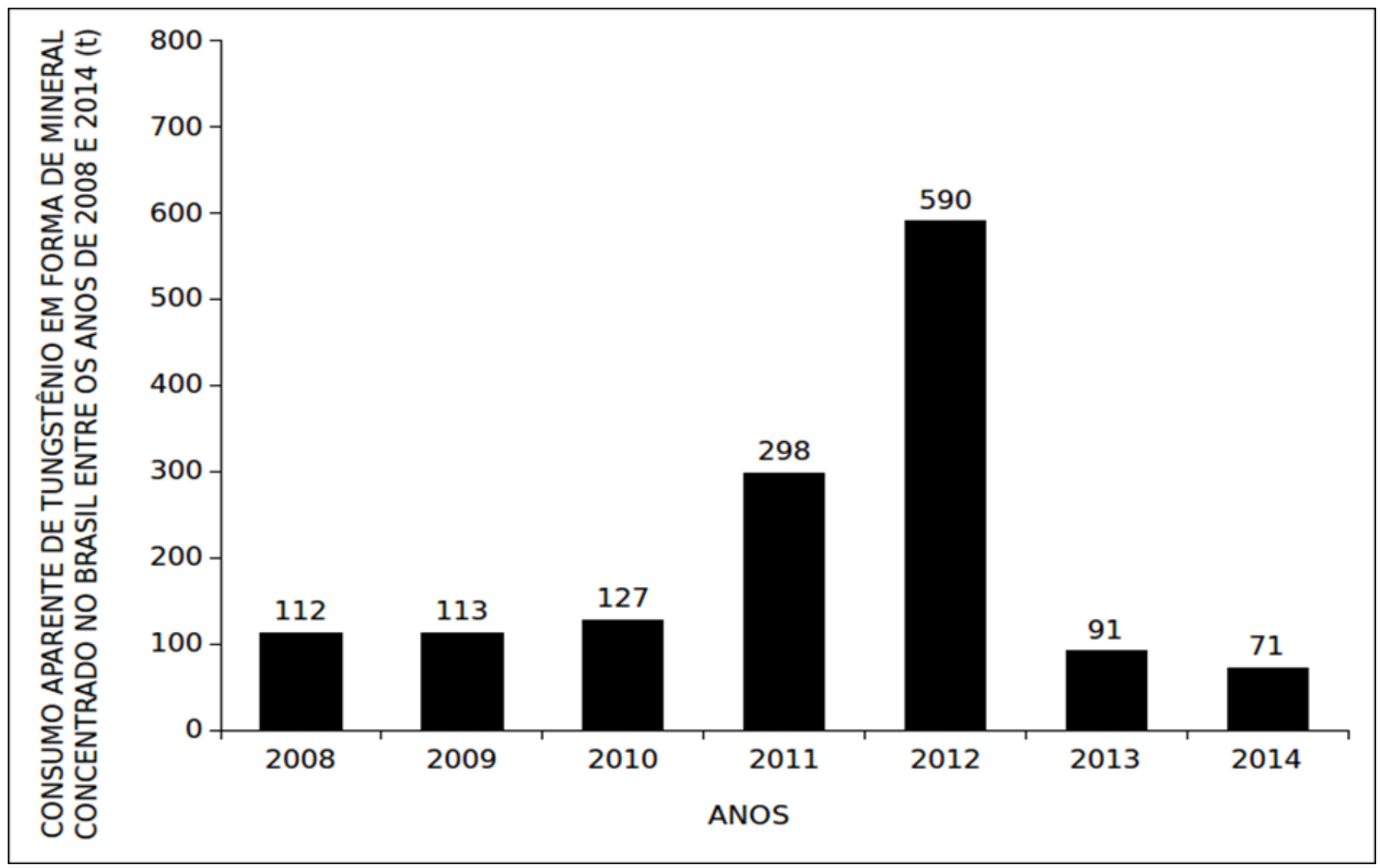

Figura 5: Consumo aparente de tungstênio em forma de mineral concentrado no Brasil entre os anos de 2008 e $2014(\mathrm{t})$.

\section{DISCUSSÃO}

A queda significativa na produção entre 2008 e 2010 pode ser consequência da baixa eficiência na recuperação de tungstênio em materiais de baixa granulometria no Brasil. Por outro lado, o aumento a partir do ano de 2011 pode ter acontecido pelo aumento de estudos para recuperar o elemento em rejeitos, quando contido em baixo teor. Métodos de lixiviação, como lixiviação com álcalis sob pressão, por exemplo, podem servir para tratar pré-concentrados com teor aproximado de 5\% da matéria-química (FERNANDES e MACHADO, 2009). a Mina Brejuí da Mineração Tomaz Salustino possuía mais de 3.000.000 toneladas de rejeito somados em suas pilhas, o que mostra que o potencial de recuperação existe (CARVALHO et al., 2002). 
Em relação ao quadro mundial, as reservas de tungstênio do Brasil cresceram de 0,39\%, em 2005, para $1 \%$, em 2006. Este crescimento promoveu maiores estudos para a determinação de tratamentos mais apropriados para o concentrado deste elemento. Os resultados destes estudos são possivelmente a causa do aumento da produção a partir do ano de 2011 (PAULINO et al., 2012).

O que provavelmente provocou o maior número de exportações foi o fato de o Brasil não produzir tungstênio metálico nos anos pesquisados. Todavia, mais da metade do tungstênio foi transformado em ligas metálicas em 2012 para a produção de lâmpadas incandescentes e canetas esferográficas. Sendo assim, provavelmente a alternativa das indústrias para utilizá-lo desta forma foi exportando as ligas metálicas (IBRAM, 2012; PAULINO et al., 2012; PAULINO e AFONSO, 2013).

A relação entre demanda e oferta, em economia, Lei da Oferta e da Procura, pode justificar a diferença de preços entre a EUA-Platts Metals Week e a Europa-London Metal Bulletin. Esta lei explica que quando há uma grande oferta e pouca procura de um produto, a tendência é de seu preço cair; do contrário, a estabilização desses dois fatores gera estabilização nos preços. Os Estados Unidos (EUA) possuem a segunda maior reserva de tungstênio do mundo, entretanto, a Europa importou mais tungstênio que os EUA, cerca de $28 \%$ da produção mundial. Além disso, dados da OEC (2014) mostram que houve maior exportação de tungstênio pela Europa em comparação com os EUA. Com esta maior quantidade de tungstênio na Europa, torna-se coerente o preço sugerido pelo seu comércio ser mais barato que o valor determinado pela fornecedora de dados americana (MIRANDA, 2012; NORONHA e GUEDES, 2014).

A ascensão do consumo aparente nacional começou em 1999 e esta ocorreu porque a produção do concentrado acompanhava a demanda do consumo interno. Entretanto, a queda no consumo nos anos de 2013 e 2014 provavelmente foi resultado da necessidade de importar produtos intermediários para o consumo doméstico. Além disso, ainda há as consequências da crise econômica que o país passou, onde houve declínio no desenvolvimento e consequentemente afetou o setor financeiro da indústria e comércio, dificultando o consumo do elemento (CANO et al., 2009; CERVO e LESSA, 2014).

\section{CONCLUSÃO}

O tungstênio é um metal que ainda precisa de mais pesquisas para continuar a aumentar sua produção e ganhar espaço na mineração brasileira. Durantes o período pesquisado, notou-se que, apesar de a produção tanto dele concentrado quanto contido aumentou anualmente, sendo afetada pela falta de exploração de reservas estratégicas ou métodos mais pragmáticos para a recuperação do metal quando há baixo teor do mesmo. A crise e a instabilidade dos comércios mundiais e nacionais afetaram o consumo e os preços do metal tanto no Brasil, quanto nas principais bolsas de valores das principais economias mundiais. O quadro brasileiro do tungstênio demonstrou dificuldades, mas continuou crescendo, trazendo pesquisas que podem melhorar o consumo e produção da matéria-prima no território nacional.

\section{REFERÊNCIAS}

BRASIL. Glossário Geológico Ilustrado. 2016. Disponível em: < http://sigep.cprm.gov.br/glossario/index.html >. Acesso em: 27 de novembro, 2017.

CANO, T. M.; COSTA, J. L.; NESI, J. R. Tungstênio. Brasília: Departamento Nacional da Produção Mineral DNPM 2009. 
CARVALHO, E. B. et al. Caracterização de rejeitos provenientes da usina de beneficiamento do minério da Mina Brejuí/RN. XIX Encontro Nacional de Tratamento de Minérios e Metalurgia Extrativa. Recife PE. 12002.

CERVO, A. L.; LESSA, A. C. The fall: the international insertion of Brazil (2011-2014). Revista Brasileira de Política Internacional, v. 57, n. 2, p. 133-151, 2014.

FERNANDES, B. B.; MACHADO, A. O. Lixiviação de Scheelita - Uma Revisão do Estado da Arte. IV Congresso de Pesquisa e Inovação da Rede Norte Nordeste de Educação Tecnológica (). Leite, J. Y. (2009). . , Belém-PA: CONNEPI 2009.

IBRAM. Você Sabe para Que Serve o Tungstênio? , 2012. Disponível em: < http://www.ibram.org.br/150/15001002.asp?ttCD_CHAVE=174627 >. Acesso em: 18 de agosto de 2018.

MIRANDA, M. B. A Lei da Oferta e da Procura e os Preços dos Produtos e Serviços. Rev. Virtual Direito Brasil, v. 6, n. 1, p. 1-2, 2012.

NORONHA, F. Minério. Rev. Ciência Elem, v. 5, n. 2, p. 18, 2017.

NORONHA, F., LIMA, A.,; GUEDES, A. Potencialidades de Portugal em minerais críticos. Geologia e Sustentabilidade, v. 2, 2014.

PAUlinO, J. F.; AFONSO, J. C. Elemento Químico: Tungstênio. Química Nova na Escol, v. 35, n. 02, p. 141-142, 2013.

PAULINO, J. F. et al. Isolamento do Tungsténio da Volframita da Mina de Igarapé Manteiga (RondôniaBrasil) por Lixiviação Ácida. Quim. Nova, v. 35, n. 9, p. 1854-1857, 2012.

${ }^{[1]}$ Estudante de Ensino Médio. Curso Técnico em Mineração. Instituto Federal de Ensino Básico, Técnico e Tecnológico do Amapá (IFAP).

[2] Tecnólogo em Materiais. Mestre em Ciência e Engenharia de Materiais. Professor Pesquisador do Instituto Federal de Ensino Básico, Técnico e Tecnológico do Amapá (IFAP)

3] Biomédica. Doutora em Doenças Tropicais. Professora Pesquisadora da Universidade Federal do Amapá (UNIFAP).[3] Biólogo. Doutor em Doenças Tropicais. Professor Pesquisador da Universidade Federal do Pará (UFPA).

[4] Biólogo. Doutor em Doenças Tropicais. Professor Pesquisador da Universidade Federal do Pará (UFPA).

[5] Teóloga. Doutora em Psicanálise Clinica. Pesquisadora do Centro de Pesquisa e Estudos Avançados, São Paulo, SP. 
${ }^{[6]}$ Biólogo. Doutor em Teoria e Pesquisa do Comportamento. Professor Pesquisador do Instituto Federal de Ensino Básico, Técnico e Tecnológico do Amapá (IFAP)

\section{PUBLIQUE SEU ARTIGO CIENTÍFICO EM:}

https://www.nucleodoconhecimento.com.br/enviar-artigo-cientifico-para-submissao 